\title{
A survey of spinal cord injuries resulting from sport
}

\author{
T Noguchi MD \\ Department of Orthopaedic Surgery, Hakone National Hospital, 412, Kazamaturi, \\ Odawara-shi, Kanagawa, Japan
}

We surveyed 35 patients who had been admitted to the Hakone National Hospital with a traumatic spinal cord injury (SCI) resulting from sports accidents, from 1975 to 1991 . There were 32 males and three females. Thirtyone patients $(88.6 \%)$ under the age of 30 had been injured. The most common sport was swimming $(51.4 \%)$, followed by gymnastics $(22.8 \%)$. The most common factors were conceit and lack of skill. The injuries were predominantly at the C4-5-6 level. Thirty-four of the patients had a cervical spine injury. Paralysis at the sixth cervical level occurred in 15 cases. Regarding the mechanism of injury, impact on the ground due to misjudgement in the depth of water was the most frequent in swimming; and failure in a somersault the most frequent in gymnastics. The most important point raised in the prevention of SCI sport was education about the dangers during elementary schooling.

Keywords: sport injury; spinal cord injury; swimming; gymnastics.

\section{Introduction}

In recent years, the population participating in sport has increased in Japan and unfortunately many kinds of sport injuries have occurred. One such injury is a spinal cord injury (SCI), which is a catastrophe, sometimes resulting in quadraplegia or paraplegia. Therefore we studied SCI from sport accidents.

\section{Material and methods}

From 1975 to 1991,35 patients were admitted to the Hakone National Hospital with traumatic SCI resulting from sport. Thirty-two patients were males, and three females. Information was obtained from the charts, roentgenograms, and interviews with patients.

\section{Results}

The incidence and sex is shown in Table I. The age distribution at the time of the accident is shown in Table II. Twenty-seven patients were interviewed about complications at the time of the accident. Head injury occurred in six patients and facial
Table I Incidence of accidents and sex

\begin{tabular}{lrcr}
\hline & Male & Female & Total \\
\cline { 2 - 4 } Swimming & 17 & 1 & 18 \\
Gymnastics & 7 & 1 & 8 \\
Rugby & 2 & & 2 \\
Rock climbing & 2 & & 2 \\
Skiing & & 1 & 1 \\
Baseball & 1 & & 1 \\
Wrestling & 1 & & 1 \\
Surfing & 1 & & 1 \\
Karate & 1 & & 1 \\
Total & 32 & 3 & 35 \\
\hline
\end{tabular}

contusion in two patients. Four cases of brain contusion and one each of facial and cerebral contusion were caused by swimming; one patient's brain contusion was caused by surfing; and one case of facial contusion was caused by skiing. Loss of consciousness at the time of the accident occurred in only two patients, both swimming accidents. Factors contributing to the injury varied and are shown in Table III. In swimming injuries, the most frequent reasons for the injury were conceit in 11 cases, and lack of skill in seven cases. In gymnastics, the most frequent reasons were poor 
Table II Age distribution in accidents

\begin{tabular}{|c|c|c|c|c|c|c|c|c|}
\hline & \multicolumn{8}{|c|}{ Age (years) } \\
\hline & $11-15$ & $16-20$ & $21-25$ & $26-30$ & $31-35$ & $36-40$ & $41-45$ & $46-50$ \\
\hline Swimming & 2 & $8^{\mathrm{a}}$ & 2 & 3 & 1 & 1 & & 1 \\
\hline Gymnastics & 1 & $5^{\mathrm{a}}$ & 2 & & & & & \\
\hline Rugby & & 2 & & & & & & \\
\hline Rock climbing & & 1 & & 1 & & & & \\
\hline Skiing & & & & & & & $1^{\mathrm{a}}$ & \\
\hline Baseball & & 1 & & & & & & \\
\hline Wrestling & & 1 & & & & & & \\
\hline Surfing & & & & 1 & & & & \\
\hline Karate & & & 1 & & & & & \\
\hline
\end{tabular}

${ }^{\mathrm{a}}$ Female.

Range $=13-47$ yrs .

Average $=22.4 \mathrm{yrs}$.

Table III Reasons for injuries $(n=27)$

\begin{tabular}{lr}
\hline Conceit & 13 \\
Lack of skill & 11 \\
Unavoidable causes & 8 \\
Lack of caution & 5 \\
Poor equipment & 5 \\
Absence of instructor & 5 \\
Lack of fitness & 1 \\
\hline
\end{tabular}

equipment and the absence of an instructor in each of the five cases.

Spinal injuries were predominant at the C4-5-6 level. All had cervical spine injuries, except for one caused by rock climbing. The level of neurological injury was from C4-L4. Fifteen lesions were at level C6 (Table IV).

Conservative treatment was used in seven cases, and surgical treatment in 28 cases.

Table IV Localisation of neurological lesions (35 cases)

\begin{tabular}{rr}
\hline $\mathrm{C} 4$ & 1 \\
5 & 6 \\
6 & 15 \\
7 & 8 \\
8 & 2 \\
$\mathrm{~T} 1$ & 1 \\
7 & 1 \\
$\mathrm{~L} 4$ & 1 \\
\hline
\end{tabular}

Anterior spinal fusion was carried out in 20 patients, laminectomy in only two, and combined anterior spinal fusion and posterior spinal fusion in six.

\section{Discussion}

According to the Japan Medical Society of Paraplegia's 1989 report, there are 46.2 cases of traumatic SCI per year per 1 million population in Western Japan. Sport accidents in this report accounted for $4.2 \% .{ }^{1}$ The incidence of SCI in sport reported over the past 10 years in Japan ranged from $2.4 \%$ to $15.5 \%$ (Kaizuka 2.4\%, ${ }^{2}$ Nihei $15.5 \%{ }^{3}$ ). Many articles reported 5\%-10\% (Table V). ${ }^{4-8}$ The most common sport involved was swimming, followed by gymnastics. The location where the injury occurred in swimming accidents over the past 10 years was reported in several studies (Table VI).$^{9}$

Table V Spinal cord injuries in sport

\begin{tabular}{lcr} 
& Incidence & $\%$ \\
\hline Hase, $1982^{8}$ & $31 / 373$ & 8.3 \\
Kaizuka, 1982 & $14 / 369$ & 2.4 \\
Yoshimura, 19907 & $46 / 762$ & 6.0 \\
Oda, 19911 & $51 / 1220$ & 4.2 \\
Oguma, 1991 & $8 / 189$ & 4.2 \\
Nihei, 19913 & $67 / 432$ & 15.5 \\
Shirasawa, 19915 & $46 / 676$ & 6.8 \\
Saito, $1991^{6}$ & $36 / 460$ & 7.8 \\
\hline
\end{tabular}


Table VI Location of occurrence of injury

\begin{tabular}{lrrrr}
\hline & Pool & Ocean & River & Lake \\
\hline Kaizuka, 1982 & 7 & 2 & & \\
Hase, 1982 & 11 & 4 & & \\
Mutou, 198310 & 13 & 13 & & \\
Suetuna, 1986 $^{8}$ & 4 & & & \\
Kishi, 1990 $^{11}$ & 4 & 10 & 1 & \\
Yoshimura, 19907 $^{7}$ & 13 & 7 & 1 & 1 \\
Noguchi, 1993 & 8 & 7 & 2 & 1 \\
& 60 & 43 & 4 & 2 \\
\hline
\end{tabular}

Swimming pools were the most common location, accounting for 60 injuries. The next most common area was the ocean, with 43 cases. Six injuries occurred in rivers and lakes. Hase reported that the most common location for injuries in swimming was swimming pools. ${ }^{8}$ But our investigation gave the same results as Mutou's: the incidence in swimming pools and the ocean was the same. ${ }^{9}$ We feel that this result varies according to the particular features of the region. We were able to interview 13 patients regarding the reason for their injury; 11 said that their face or head hit the bottom, but only four sustained injuries to the face or head. Three patients hit a rock or a large stone, and one struck the bottom of the swimming pool. This phenomenon suggests that striking the sandy bottom off shore or the bottom of a swimming pool cannot easily cause a laceration. One patient's accident was considered to be the same as in the case reported by Kewalramani. ${ }^{13}$ The reason was striking the water surface. The events during which the injuries occurred in gymnastics were floor exercise in four cases, the horizontal bar exercise in two cases and the vault in two cases. All patients were injured in attempts to perform a forward or backward somersault. This is the same as in Mituki's report. ${ }^{14}$ As a reason for an injury in swimming, factors of conceit, poor skill, an unfamiliar place and a misjudgement of the depth of the water were the most frequent.

In gymnastics, a defect in the equipment and the absence of an instructor were the most frequent factors. Patients doing gymnastics complained that the instructor was absent at the time of the accident; this was characteristic of gymnastics.

We were surprised that awareness of the accident was quite clear in 25 of 27 cases. ${ }^{15}$ This led to the need to give artificial respiration immediately for only one case because of loss of consciousness. Twentyfive patients were able to personally request artificial respiration. We think that this state could prevent secondary injury to the spinal cord (mainly the cervical spinal cord).

Concerning the type of injury, excluding two cases with no radiological evidence, there were 16 compression or burst fractures, and 17 fracture dislocations. There were many compression or burst fractures from swimming, but there were also many fracture dislocations in other sports. This suggested that the mechanism of injury was mainly an axial loading stress in swimming. ${ }^{16}$ The neurologically deficient level ranged from the fourth cervical segment to the fourth lumbar segment. Paralysis at the sixth cervical level occurred in 15 cases, the same high frequency as in other reported cases.

This survey showed that SCI in sport, except in a rock climbing case, resulted in a cervical SCI. It was catastrophic. Important matters in the prevention of SCI in sport are not only the rules or the equipment for an exercise but also education about the possible dangers of SCI, and should be taught in elementary school. For example, when learning to swim it is important to hold the head between the elevated arms to prevent SCI. On the other hand, in gymnastics, the presence of an instructor during practice is essential.

\section{References}

1 Oda $\mathrm{H}$, Shingu $\mathrm{H}$ et al (1991) Incidence of acute traumatic hospitalized spinal cord injury in Western Japan. J Japan Med Soc Paraplegia 4: 38-39

2 Kaizuka T, Ogino H, Sasaki T, Kawazu N, Sakai N, Ohkawa A et al (1982) Spinal cord injuries from diving accidents. Orthop Surg Traumatol 25: 637-641. 
3 Nihei R, Suyama T, Tobimatu H, Tobimatu Y, Matuoka M, Kimura T et al (1991) Cervical cord injury due to sport accidents and its prevention. J Japan Med Soc Paraplegia 4: 46-47.

4 Oguma T, Matuno M (1991) Causes and incidence of spinal cord injury in Hokkaido. J Jpn Med Soc Paraplegia 4: 42-43.

5 Shirasawa K, Shiba K, Katuki M, Ohta H, Mori E, Rikimaru S et al (1991) Etiology of vertebral and spinal cord injury. J Jpn Med Soc Paraplegia 4: 54-55

6 Saito M, Ohtani K, Shibazaki K, Kenmochi K, Tezuka M, Haga C (1991) Statistics of spinal cord injuries. J Japan Med Soc Paraplegia 4: 56-57.

7 Yoshimura T, Shiba K, Katuki M, Ueta T, Shirasawa K, Murao T, Mori E, Ishibashi Y, Yu S (1990) Injuries of the spine and the spinal cord in sports. J West Jpn Res Soc Spine 16: 23-27.

8 Hase H, Fujimura Y, Manzoka S, Shibazaki K, Ohtani K (1982) Spinal cord injuries resulting from sports. Clin Orthop Surg 17: 118-124.

9 Suetuna F, Tohno S, Harata S, Ohmi Y, Ohtake S, Nakano K (1986) Injuries of the cervical spine and spinal cord in sports. JJTOM 34: 674-678.

10 Mutou Y, Fukashiro S, Nakamura Y, Kobayashi T, Ishikawa M, Mori T (1983) Mechanism and prevention of cervical spine injuries resulting from diving accidents (Part 1). Clinical aspects Jpn J Sports Sci 2: 655-659.

11 Kishi K, Nagata Y, Murase M, Amano K, Ohmoto O, Kinoshita H (1990) Cervical spine and spinal cord injuries due to diving accident. J Clin Sport Med 7: 149-153.

12 Noguchi T, Yoshima H, Kitano Y, Arima T (1993) A survey of spinal cord injuries from diving. Jpn J Orthop Sport Med 12: 69-71.

13 Kewalramani LS, Taylor RG (1975) Injuries to the cervical spine from diving accidents. J Trauma 15: 130-142.

14 Mituki N, Takazawa H, Satou I, Takamura K, Hamahashi M, Itou S (1982) Statistical observation of spinal cord injuries in high school student's gymnastic exercises. Jpn J Orthop Sports Med 1: 7-11.

15 Steinbrück K, Paeslack V (1980) Analysis of 139 spinal cord injuries due to accidents in water sports. Paraplegia 18: 86-93.

16 Good RP, Nickel VL (1980) Cervical spine injuries resulting from water sports. Spine 5: 502-506. 